\title{
Thyroglossal Duct
}

National Cancer Institute

\section{Source}

National Cancer Institute. Thyroglossal Duct. NCI Thesaurus. Code C49783.

A tube-like structure present in the developing embryo that connects the area in which the thyroid gland initially develops, the oropharynx, to the final position of the thyroid gland in the newborn. This structure normally atrophies prior to birth but may persist in some cases. 